\title{
Influence of Pansharpening in Obtaining Accurate Vegetation Maps
}

\author{
Edurne Ibarrola-Ulzurrun ${ }^{\mathrm{a}, \mathrm{b}}$, Consuelo Gonzalo-Martín $\oplus^{\mathrm{b}}$, and Javier Marcello ${ }^{\mathrm{a}}$ \\ a Instituto de Oceanografía y Cambio Global (IOCAG), Universidad de Las Palmas de Gran Canaria (ULPGC), Parque Científico Tecnológico Marino \\ de Taliarte, s/n, 35214, Telde, Las Palmas, Spain; ${ }^{b}$ Escuela Técnica Superior de Ingenieros Informáticos, Universidad Politécnica de Madrid, UPM, \\ Campus de Montegancedo, 28223, Pozuelo de Alarcón, Madrid, Spain
}

\begin{abstract}
In recent decades, there has been a decline in ecosystem services. Thus, the development of reliable methodologies to monitor ecosystems is becoming important. In this context, the availability of very high resolution sensors offer practical and cost-effective means for good environmental management. However, improvements in the data received are becoming necessary to obtain higher quality information in order to get reliable thematic maps. One improvement is pansharpening, which enhances the spatial resolution of the multispectral bands by incorporating information from a panchromatic image. The main goal of this work was to assess the influence of pansharpening techniques in obtaining precise vegetation maps. Thus, pixel- and object-based classification techniques were implemented and applied to fused imagery using different pansharpening algorithms. Worldview-2 high resolution imagery was used due to its excellent spatial and spectral characteristics. The Teide National Park, in The Canary Islands (Spain), was chosen as the study area since it is a vulnerable heterogeneous ecosystem. The vegetation classes of interest considered were established by the National Park conservation managers. Weighted Wavelet 'à trous' through Fractal Dimension Maps pansharpening algorithm demonstrated a superior performance in the image fusion preprocessing step, while the most appropriate classifier to generate accurate vegetation thematic maps in heterogenic and mixed ecosystems was the Bayes method after the segmentation stage, even though Support Vector Machine achieved the highest overall accuracy.
\end{abstract}

\section{RÉSUMÉ}

Au cours des dernières décennies, les ressources naturelles ont diminué. Pour ces raisons, le développement de méthodologies fiables de surveillance des écosystèmes devient de plus en plus important. Dans ce contexte, la disponibilité de satellites à très haute résolution offre des moyens pratiques et rentables pour une bonne gestion environnementale. Cependant, il est d'abord nécessaire d'introduire des améliorations dans l'acquisition de données afin d'obtenir des informations de meilleure qualité permettant la création des cartes thématiques fiables. Une de ces améliorations est le "pansharpening", qui augmente la résolution spatiale des bandes multispectrales en incorporant de l'information à partir de l'image panchromatique. Le but principal de ce travail était d'évaluer l'influence des techniques de pansharpening dans l'obtention de cartes de végétation précises. Pour ce faire, on a mis en place des techniques de classification par pixel et orientée-objet, et on les a appliquées à l'imagerie fusionnée en utilisant différents algorithmes de "pansharpening". L'imagerie à haute résolution Worldview-2 a été utilisée en raison de ses excellentes caractéristiques spatiales et spectrales. On a choisi le Parc National du Teide, aux Canaries (Espagne), comme zone d'étude, étant donné qu'il s'agit d'un écosystème vulnérable et hétérogène. Les classes de végétation considérées ont été établies par les responsables de la conservation du Parc National. L'algorithme de pansharpening "Weighted Wavelet 'à trous' through Fractal Dimension Maps" a démontré la précision la plus élevée à l'étape de prétraitement de fusion d'images, alors que le classificateur le plus approprié pour générer des cartes précises de végétation, dans les écosystèmes hétérogènes et mixtes, a été la méthode Bayes, après l'étape de segmentation, bien que Support Vector Machine a obtnenu le plus haut précision globale.

\section{ARTICLE HISTORY}

Received 1 February 2017

Accepted 9 August 2017

\section{Introduction}

Biodiversity supports a wide variety of ecological functions together with the services provided by ecosystems (Isbell et al. 2011). Its conservation is related to global environmental changes, such as the land use changes, climate change, and sustainable developments. However, during the last century, human activity gave raise to alterations in ecosystems and thus, biodiversity is suffering a fast decline (Khare and Ghosh 2016). This creates a demand to preserve environmental resources 
(Pakzad et al. 2003). Remote sensing has become an essential tool for evaluating and monitoring ecosystems. It is able to provide consistent data on the Earth at various scales, reducing the collection of field data and ground-based observations (Khare and Ghosh 2016), making it a cost-effective tool for land-cover classification, monitoring, and environmental management (Aplin 2004). Procedures for both classifying land cover and monitoring land cover changes are extensively used in environmental management. However, classifying remotely sensed data in a thematic map remains a challenge because of the many factors involved, which may affect the success of the classification (Lu and Weng 2007), i.e., the complexity and heterogeneity of small species in the ecosystem, quality of the remotely sensed data available, as well as the image preprocessing and classification approaches. Remote sensing classification involves the selection of training samples, image pre-processing, a suitable classification model, post-classification processing, and accuracy assessment (Lu and Weng 2007). In this context, pixel-based and object-based classification approaches can be distinguished.

In the traditional pixel-based classification approaches, each pixel is identified by comparing its spectral signature value with the training samples and that pixel is labeled with the proper class based on a certain supervised algorithm (Gao et al. 2009), but neither spatial concepts nor contextual information are incorporated. Thus, the misclassification rate could be high due to the spectral similarity characteristics of some classes, the spectral variability of the canopy reflectance and the presence of mixed pixels located on the boundary between classes (Peña-Barragán et al. 2011). On the other hand, object-based image analysis or OBIA, in the geographic context (GEOBIA), was proposed as a new classification approach due to the launch of very high resolution (VHR) sensors. It offers a methodological framework, from a machine-based interpretation of complex classes, defined by the spectral, spatial, structural and hierarchical properties (Blaschke et al. 2008; Goodin et al. 2015, Oruc et al. 2004). The idea of OBIA is the segmentation of the image followed by successive analyses, usually at different hierarchical levels, in order to create relationships within segments or objects (Garcia-Pedrero et al. 2015; Lantz and Wang, 2013; Peña-Barragán et al. 2011). Given that, segmentation could be defined as a bottomup region-merging process in which the image is subdivided into homogeneous regions according to several parameters (band weights, scale, color, shape, texture, etc.) defined by the operator, with the objective of creating object delimiting borders (Peña-Barragán et al. 2011). However, segmentation could be a challenge because the quality of the classification results depends largely on the segments obtained, thus, it is necessary to establish a balance between efficacy and efficiency (Garcia-Pedrero et al. 2015).

As previously mentioned, remote sensing imagery requires a number of corrections and enhancements, before starting with the classification approach. Since, VHR sensors provide both a multispectral image and a panchromatic band, the quality enhancement would be carried out using an image fusion technique (pansharpening algorithm) in which the spatial resolution of the multispectral image can be improved by incorporating information from the panchromatic image (Carper et al. 1990; Chavez et al. 1991; Shettigara 1992). Extensive research into image fusion has been carried out during the last decades. Image fusion can be categorized into 3 levels: pixel level, feature level, and knowledge or decision level. Specifically, pansharpening is performed at pixel level and ideal pansharpening algorithm should have 2 main attributes (Li et al. 2012): (i) enhancing high spatial resolution; and (ii) reducing spectral distortion. The simplest pansharpening methods, at the conceptual and computation level, are Intensity-Hue-Saturation (IHS; Carper et al. 1990; Shettigara 1992), Principal Component Analysis (PCA; Chavez et al. 1991) and Brovey Transforms (Gillespie et al. 1987). However, these techniques have problems because they provide spectral distorted fused images. New approaches such as Wavelet transformation and the High Pass Filtering (Alimuddin et al. 2012; Alparone et al. 2016; Chavez et al. 1991; González-Audícana et al. 2004; Kpalma et al. 2014; Marcello et al. 2013; Pohl 2014; Vivone et al. 2015) have been proposed to address particular problems with the previous techniques (Aiazzi et al. 2002, 2006; Nuñez et al. 1999).

In addition, images acquired from VHR sensors require atmospheric corrections to transform the top of atmosphere radiance into ground reflectance by removing the atmosphere absorption and scattering effects (Marcello et al. 2016), and image orthorectification, as the topographic relief decreases or increases the radiance illuminated because of the difference in land elevation in some areas. Once images have been corrected and enhanced, the generation of products for the management of natural resources can be carried out.

In this context, the main goal in this study was to implement and assess pixel- and object-based classifiers on VHR imagery that were fused using different pansharpening techniques. Thus, the influence of fusion on the classification results was analyzed. The ultimate purpose was the development of a reliable processing methodology which, when applied to remote sensing imagery, serves to obtain accurate vegetation maps and information for the conservation of natural resources. 


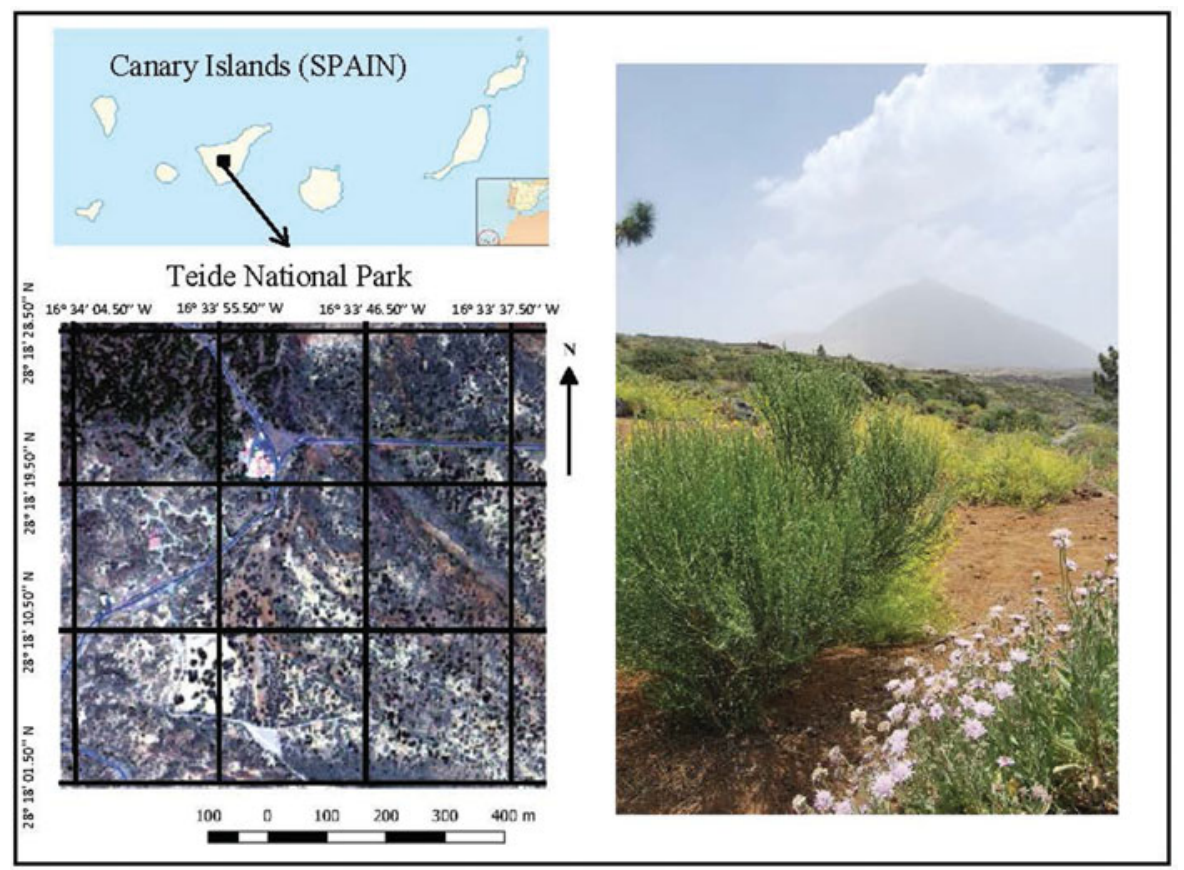

Figure 1. Study area of Teide National Park (Canary Islands, Spain).

Specifically, a very complex shrubland ecosystem has been selected to perform the analysis.

The article is structured as follows: The 2nd section includes the study area and a description of the data sets, the image fusion methods, and the different classification techniques applied at pixel- and object-based levels. The analysis and evaluation of the different techniques, as well as the thematic maps obtained are presented in the $3 \mathrm{rd}$ section. Finally, the last section includes a critical analysis of the results and summarizes the main outcomes and contributions.

\section{Material and methods}

\section{Study area and dataset}

A heterogeneous ecosystem of The Canary Islands $\left(28^{\circ}\right.$ $06^{\prime} \mathrm{N} ; 16^{\circ} 33^{\prime} \mathrm{W}$ ) was selected for this study: the Teide National Park located on the island of Tenerife (Figure 1). The Teide National Park, created in 1954, is a protected area with 18,990 hectares (Martín-Osorio et al. 2005), located on the island of Tenerife. The Teide National Park area is a giant crater situated in the center of the island. Teide is made up by several overlapping volcanoes in the middle of the giant crater, making it the highest mountain in Spain (3,718 m; González-Lemus et al. 2009). As already mentioned, the vegetation is vulnerable to environmental changes. Thus, the plants respond to thermic and hydric stress, a characteristic of a mountain ecosystem with a shrub physiognomy (Arozena-Concepción and Beltrán-Yanes 2006).
The following non-herbaceous vegetation species were selected for the study by the experts of the National Park, due to their abundance and importance at the ecological level: Spartocytisus supranubius (Teide broom), Pterocephalus lasiospermus (Rosalillo de cumbre), Descurainia bourgaeana (Hierba pajonera), and Pinus canariensis (Canarian pine; Figure 2). All of them are addressed in this article as "vegetation classes." Moreover, urban, road, and bare soil classes were also included in the classification.

The Teide broom (Spartocytisus supranubius; Bonet et al. 2009) is a broom-like shrub reaching a height of $2 \mathrm{~m}-3 \mathrm{~m}$, moreover it is a strong competitor and its growth is a major factor affecting the composition of plant species (Kyncl et al. 2006). S. supranubius is 1 of the most important plant species as is Pterocephalus lasiospermus (Rosalillo de cumbre) and Descurania bourgaeana (Hierba pajonera; Arozena-Concepción and Beltrán-Yanes 2006). P. lasiospermus is a small shrub characterized by pink flowers appearing in the spring and $D$. bourgaeana is a shrub that can be easily distinguished by its semi-spherical shape and its flowers of yellow petals. Another significant plant species is the Canary pine (Pinus canariensis), the only native pine in the archipelago, which is found in the northern area of the park. This species has a great resistance to fire and cold temperatures (Garzón-Machado et al. 2011; Otto et al. 2012; Wildpret de la Torre 2001). Other similar shrubland ecosystems can be identified around the world, for example: Pico do Pico in the Azores, Mt. Halla in South Korea, and Hawaii or the Galapagos Islands, some areas 


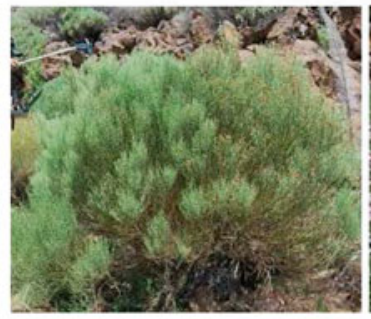

a)

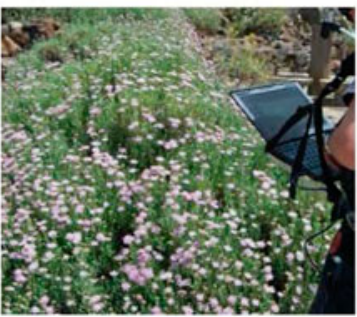

b)

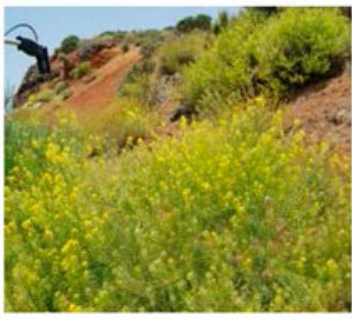

c)

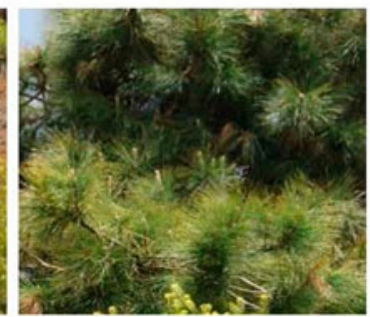

d)

Figure 2. Vegetation field campaign in the Teide National Park: (a) Spartocytisus supranubius; (b) Pterocephalus lasiospermus; (c) Descurainia bourgaeana; and (d) Pinus canariensis.

of Okanagan Desert in Canada. Thus, the importance of studying this ecosystem is its similarity to other Mediterranean, temperate or tropical parts of the world (Ruocco et al. 2014).

Worldview-2 (WV-2) orthoready imagery was used in the study. The WV-2 satellite, launched by DigitalGlobe on October 8, 2009, was the first commercial satellite to have a very high spatial resolution sensor with 1 panchromatic and 8 multispectral bands. The Teide image was acquired on May 16, 2011, in the spring season as the vegetation species has greater spectral separability (González-Lemus et al. 2009; Wildpret de la Torre 2001).

\section{Image corrections and enhancements}

Numerous methodological problems are associated with the use of data from VHR sensors (Franklin and Wulder 2002), thus, several image enhancements must be carried out in order to reduce these problems and to obtain high quality products which will allow a comprehensive and useful analysis of the natural resources.

\section{Pansharpening techniques}

The first step was to generate a pixel-level fused image, with a high spatial and spectral quality, using a pansharpening process. The enhancement is important in this type of heterogeneous ecosystem due to the small size of some vegetation classes. After a comprehensive review of the state-of-art (Ibarrola-Ulzurrun et al. 2017), 7 pansharpening methods were applied (for detailed information see the references):

- Gram-Schmidt (GS): A low-resolution PAN image is simulated and the GS transformation is performed on the simulated PAN plus the MS bands. Then, the original PAN replaces the first GS band and the inverse transform is applied (Laben and Brower 2000).

- Fast Intensity Hue Saturation (FIHS): It uses the spectral bands and the IHS transformation to estimate the new component $I$. The spatial detail is extracted, computing the difference between the panchromatic band and $I$. Finally, it is injected into the multispectral bands (Marcello et al. 2013; Tu et al. 2001; Vivone et al. 2015).

- Hyperspherical Color Sharpening (HCS): It is an algorithm specifically designed for the WV-2 sensor, based on the transformation between any native color space and the hyperspherical color space ( $\mathrm{Li}$ et al. 2012, 2013; Padwick et al. 2010; Tu et al. 2012; Wu et al. 2015).

- Based Modulation Transfer Function (MTF): The trendy implementations provided by Vivone et al. 2015 (http://openremotesensing.net/knowledgeba se/a-critical-comparison-among-pansharpeningalgorithms/) of 2 different MTF fusion algorithms were used: the one based on Generalized Laplacian Pyramid (MTF_GLP; Aiazzi et al. 2002, 2006) and the Generalized Laplacian Pyramid plus a High Pass Modulation (MTF_GLP_HPM; Burt and Adelson 1983; Aiazzi et al. 2002, 2006; Amro et al. 2011).

- Wavelet 'à trous' (WAVE_ATROUS): The fused images are obtained by adding the panchromatic wavelet planes to the multispectral image approximation (Amolins et al. 2007; Amro et al. 2011; Dutilleux et al. 1987; Gonzalo-Martín and LilloSaavedra 2008; Lillo-Saavedra and Gonzalo 2006; Marcello et al. 2013; Wald et al. 1997).

- Weighted Wavelet 'à trous' method through Fractal Dimension Maps (WAT $\otimes$ FRAC; Lillo-Saavedra and Gonzalo 2006): It is based on the wavelet 'à trous'. A mechanism that controls the trade-off between the spatial and spectral quality by introducing a weighting factor for each band $\alpha_{i}(x, y)$ for the panchromatic wavelet coefficients is established and defined as Fractal Dimension Map with the same size as the original image (Lillo-Saavedra et al. 2011). These maps are generated for each of the source images with the box-counting algorithm and by applying a windowing process. Each element in these maps provides a different weighting value for each pixel and each band. 
Quality evaluation is a fundamental issue to benchmark and optimize different pansharpening algorithms (Marcello et al. 2013; Rodríguez-Esparragón 2015; Wald 2000; Wang and Bovik 2002). A visual and quantitative assessment was undertaken in order to evaluate the pansharpening results in the different fused images. The quality assessment was carried out for the whole set of bands. In the study, a number of statistical evaluation indices were used to measure the quality of the fused images at the spectral, spatial and global level (Alparone et al. 2008; Kpalma et al. 2014; Shridhar and Alvarinho 2013). The indices applied to measure the spectral quality of the fused images, which take the original multispectral bands as a reference, were: Spectral Angle Mapper (Kruse et al. 1993; best value closer to 0) and Spectral ERGAS (Wald, 2000; best values closer to 0 , but usually between $0-3$ ). The spatial quality assesses the spatial detail injected and the panchromatic band was chosen as a reference. The indices considered were: Spatial ERGAS (Lillo-Saavedra et al. 2005; best values closer to 0, but usually between 0 3); Frequency Comparison (Rodríguez-Esparragón et al. 2014; values between $0-1$, best closer to 1); and Zhou Index (Zhou et al. 1998; values between 0-1, best closer to 1). Finally, at global level the Q8 index, which is a generalization of the Q index, (Wang and Bovik 2002) and of the Q4 index (Alparone et al. 2004), with values between 0-1 (best closer to 1), was used to measure correlation, mean shifts, and radiometric distortion simultaneously (Marcello et al. 2013).

As the Teide ecosystem is very heterogeneous and composed by small shrubs, pansharpening will be very important to achieve reliable vegetation maps. Also, both qualities will be critical, the spatial to discriminate the small plants and the spectral to differentiate similar covers. As indicated in Thomas et al. (2008), the ideal fusion method does not exist yet, but the fused results generally correspond to a tradeoff between a good geometrical representation of structures and a good representation of spectral information.

\section{Orthorectification and atmospheric correction}

After detailed assessment of different image and modelbased atmospheric corrections algorithms using WV-2 imagery and field spectroradiometer data collected simultaneously (Marcello et al. 2016), the FLAASH algorithm (Adler-Golden et al. 1999) achieved the best performance. The appropriate atmospheric parameters were adjusted (atmospheric model, aerosol model, aerosol optical thickness, adjacency, etc.) using climatologic information and field data and the average reflectance estimations achieved a Root Mean Square Error (RMSE) around 3\% when compared to the in-situ measurements. Orthorectification, using the Rational Polymodal Coefficients model, was carried out using ENVI 5.0 software (ENVI 2004) and the average RMSE after the orthorectification was $3.11 \mathrm{~m}$ for geodesic points located in the park.

\section{Segmentation at object-based approach}

The OBIA process starts with a segmentation of the input images into local groups of pixels (segments) that become spatial units in the later classifications and accuracy assessment. The object shape, size and spectral properties depend on both the segmentation approach and the research goals. The ideal purpose of the segmentation is to approximate meaningful landscape entities recognizable at a given image resolution (Dronova 2015). Image segmentation in eCognition is not a straightforward process and finding useful segmentation levels is an iterative process (Walsh et al. 2008). The most popular segmentation carried out by eCognition users (Burnett et al. 2003; Dronova 2015; Lu and Weng 2007; Walsh et al. 2008) is Multiresolution Segmentation. It is regarded as a regionbased algorithm, which starts by considering each pixel as a separate object. Subsequently, pairs of image segments are merged to form bigger segments. The decision to merge is based on the homogeneity criterion, which measures how homogeneous or heterogeneous an image object is within itself. The derived image objects in eCognition are determined by the following parameters (Baatz et al. 2001):

- Weight of image channels to assign different importance to each image band.

- Scale to determine the maximum heterogeneity of the objects allowed. Smaller scales increase the dimensionality and the division of the objects into the sub-groups, while larger scales combine the multi-segments into 1 (Marangoz et al. 2006).

- Shape to adjust the homogeneity of the object generation.

- Compactness to determine whether the objects will become more compact or smoother.

Once the Multiresolution Segmentation was performed, Spectral Difference algorithm was used to merge neighboring image objects when the difference between their layers mean intensities are below the value given by the maximum spectral difference (Baatz et al. 2001).

\section{Classification models}

Several classification techniques were applied in the study. The first step was to determine the classes appearing in the image and to obtain a set of training and testing samples. The size and representativeness of the set of the training samples are critical for image classification (Lu and Weng 2007). The second step was to determine the classification 
Table 1. Pixel-based and object-based classification algorithms and their parameters.

\begin{tabular}{lll}
\hline Classification Approach & Classification Algorithm & \multicolumn{1}{c}{ Parameters } \\
\hline Pixel-based approach & Maximum Likelihood & Threshold: 0.25 \\
& Mahalanobis Distance & Maximum distance error: None \\
& & Kernel: Radial basis function \\
& & Gamma in kernel function: 0.5 \\
Object-based approach & Bayes & Penalty parameter: 200 \\
& Nearest Neighbor & eCognition does not allow to set parameters with this classifier \\
& K-Nearest Neighbor & eCognition does not allow to set parameters with this classifier \\
& Support Vector Machine & K: 20 \\
& & Kernel: Radial basis function \\
& & Gamma in kernel function: 0.5 \\
\end{tabular}

model to be used and which classifier apply in each model. An evaluation of the parameters chosen in each classifier was performed. However, these parameters are image dependent, and the user should analyze which parameters are more suitable for their images. The 2 classification approaches considered here were pixel-based, which was carried out using ENVI 5.0 image processing software (Exelis Visual Information Solutions, Inc., a subsidiary of Harris Corporation); and object-based using eCognition Developer (Trimble Geospatial). eCognition is optimized for the cost-effective OBIA classification of VHR imagery.

The classification models selected for carrying out the pixel-based classification approach are Maximum
Likelihood, Mahalanobis Distance, and Support Vector Machine. Regarding the OBIA approach, Bayes, Nearest Neighbor, K-Nearest Neighbor, and Support Vector Machine were selected (Table 1). For choosing the classifiers' parameters, different trials were performed and evaluated until obtaining the most suitable parameter value for each classifier.

Thematic maps were obtained after applying the different classification techniques using the same training samples. Afterwards, the accuracy of the classification was measured by using the testing samples collected. In order to obtain a reliable thematic map, the training and testing samples were selected with the help of Teide
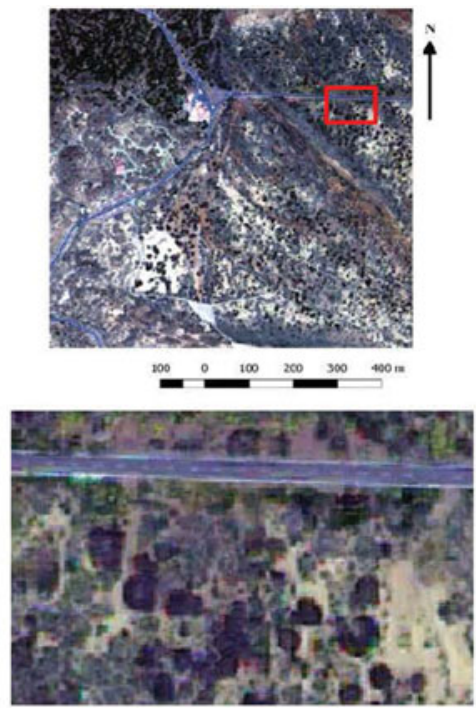

c)

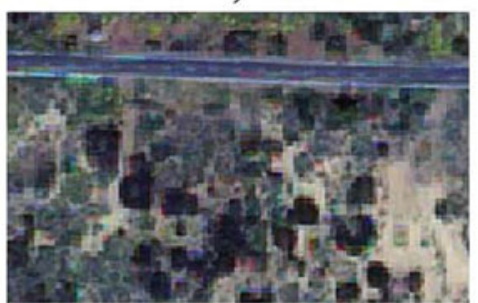

f)

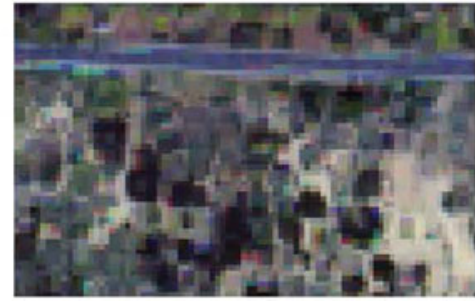

a)

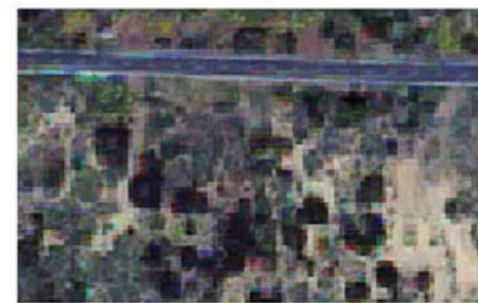

d)

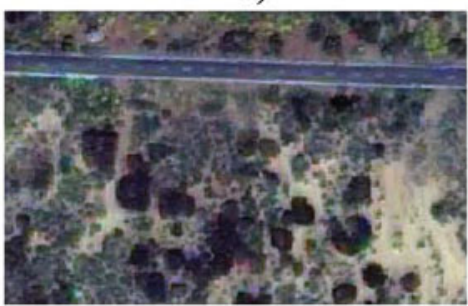

g)

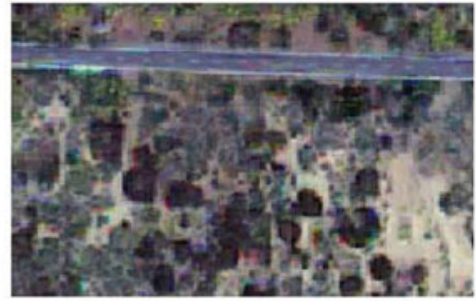

b)

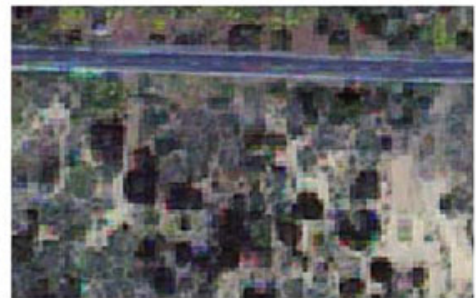

e)

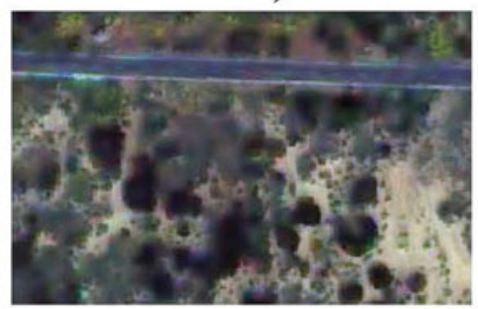

h)

Figure 3. True color images of the Teide National Park: (a) original multispectral image; and fused imagery using: (b) GS; (c) FIHS; (d) HCS; (e) MTF_GLP; (f) MTF_GLP_HPM; (g) WAVE_ATROUS; and (h) WAT $\otimes$ FRAC. 
a)

c)
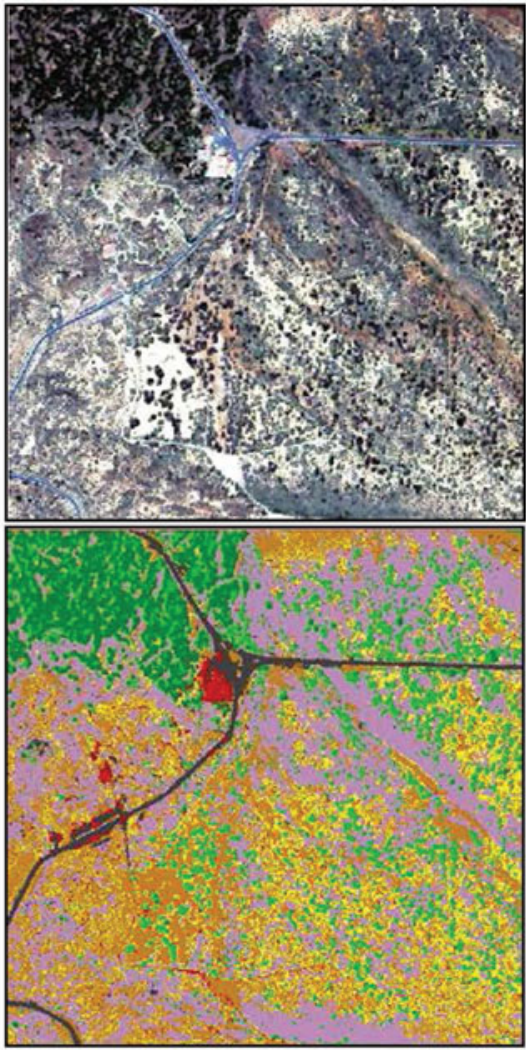

e)

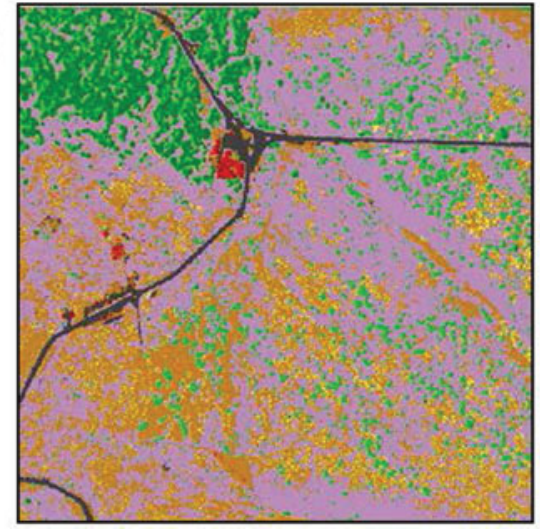

b)

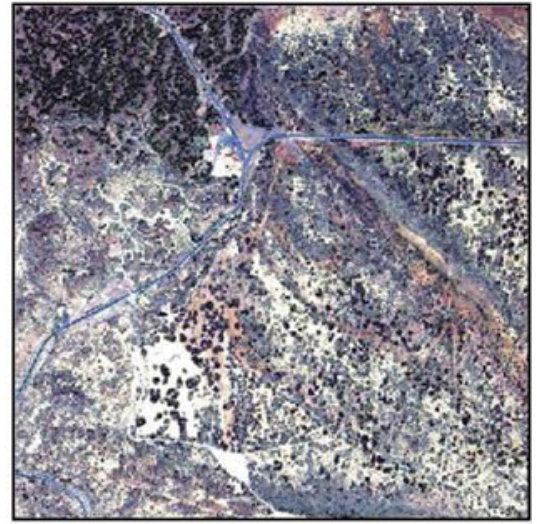

d)

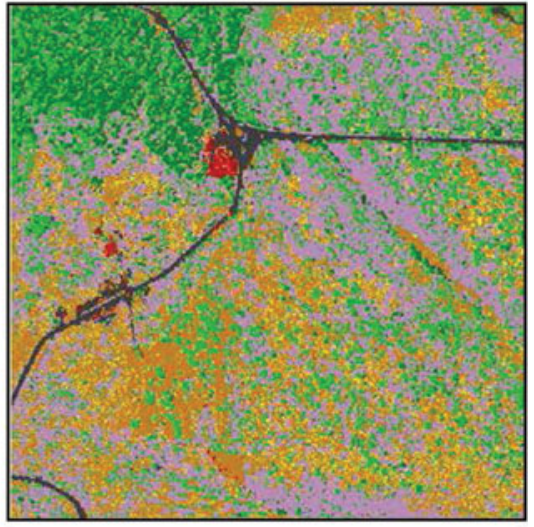

Urban

P. lasiospermus

Road

S. supramubius

P. canariensis

D. bourgaeana

Bare soil

Figure 4. RGB color composite: (a) WAT $\otimes F R A C$ fused image and (b) WAVE_ATROUS fused image; and thematic maps using: (c) Maximum Likelihood in WAT $\otimes$ FRAC fused image; (d) Mahalanobis Distance in WAVE_ATROUS fused image; and (e) Support Vector Machine in WAT $\otimes$ FRAC fused image.

National Park experts from well-known sites around the park and using the ground truth samples obtained during the fieldwork carried out in the study area, which were used for the training and testing phases in the classification process. The method used for choosing the samples was a random method in which a total of 362,631 pixels (ca. $70 \%$ of the total samples) were chosen as training samples and 159,182 pixels (ca. $30 \%$ of the total samples) for the testing.

The statistical accuracy assessment technique used in the study was the standardized confusion Error Matrix which reports 2 measurements of accuracy: Overall Accuracy and Kappa coefficient (Congalton 1991). It is more appropriate in difficult classification approaches, assuming that the map categories are mutually exclusive and exhaustive and that each location belongs to a single category. On the other hand, the Kappa coefficient is a measure of overall statistical agreement, which takes non-diagonal elements into account ( $\mathrm{Lu}$ and Weng 2007).

\section{Results and discussion}

The following results are presented as: $(i)$ analysis and evaluation of the fused images quality obtained through the different pansharpening techniques; (ii) accuracy of 


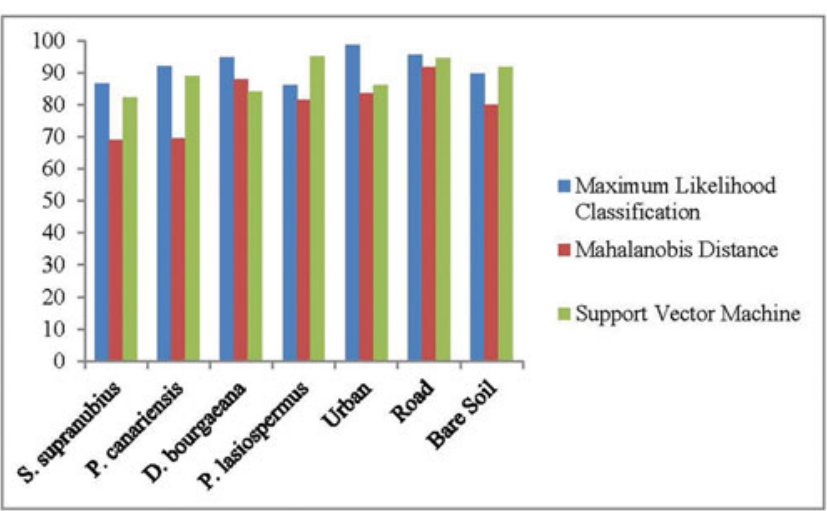

Figure 5. Classification overall accuracy in percentage (\%) of each class and classifier in the fused imagery. $X$ axis: classes; $Y$ axis: percentage value.

the pixel-based thematic maps obtained for each fused image; and (iii) accuracy of the OBIA classification results obtained for each fused image.

\section{Pansharpening results}

In this section, a visual and a quantitative assessment of the fused images are presented. To facilitate the visual inspection and for a detailed spatial analysis, a zoom of the complete scene is shown in Figure 3.

The visual interpretation at the spectral level in the image indicates that every algorithm seems to correctly preserve the spectral information in the fused image. Moreover, the differences are clearer spatially than spectrally. For HCS and MTF-based techniques, although they maintain the spectral information well, the spatial details are not satisfactorily injected, thus not achieving a good spatial enhancement. This smoothed aspect appearing in the image is because the algorithm makes uniform the areas with a common texture. Thus, Dimensional Fractal Maps are calculated into the MS and the PAN image, giving information regarding roughness in the image areas. Then, a small amount of the spatial information is incorporated in homogeneous areas, maintaining a more homogeneous spectral response, closer to the original multispectral image, avoiding in this way, the 'salt\&pepper' effect.

As it was mentioned, in order to carry out an objective evaluation of the pansharpening techniques, 6 quality indices were computed. The results are presented in Table 2. Spectral Quality indices and Q8 confirm that MTF methods provide better spectral performance while WAVE_ATROUS gets, in general, the lowest spectral quality, even though there is not great difference between the highest and the lowest result. As regards the spatial performance, WAVE_ATROUS is confirmed as the best spatial quality method. Furthermore, these results confirm the trade-off between the spectral and spatial quality of pansharpening techniques. As next presented, WAT $\otimes$ FRAC will be the most suitable technique followed by WAVE_ATROUS, taking into account the balance between a good geometrical representation of structures and a good representation of spectral information (Thomas et al. 2008).

\section{Pixel-based classification results}

Before performing the classification process, the JeffriesMatusita Distance algorithm was carried out in order to check the ROIs separability. This distance provides for most of the class pairs a value of higher than 1.8 , indicating a good separability for most of the ROIs.

Three supervised classification methods were applied to each fused image (Table 1). Table 3 shows the Overall Accuracy as well as the Kappa coefficient for each classification technique applied to each fused image.

The best result for both Maximum Likelihood and Support Vector Machine classification is obtained in the WAT $\otimes$ FRAC fused image, whereas the WAVE_ATROUS fused image obtains the best accuracy with Mahalanobis Distance classification. Every classifier performs a good classification, which is more significant both in Maximum Likelihood and Support Vector Machine, with Kappa coefficients of 0.76 and beyond. Furthermore, the Support Vector Machine achieves the highest accuracy with the WAT $\otimes$ FRAC fused image. Finally, it is observed how the WAVE_ATROUS and WAT $\otimes$ FRAC algorithms, which obtain higher values in the quantitative spatial indices (Table 2), improve the classification compared with the original multispectral image and the remaining pansharpening techniques. These results highlight the importance of the spatial information in the Teide National Park where vegetation species are mixed and are limited in size.

In more detail, thematic maps for the best pansharpening algorithm are shown in Figure 4 for Maximum Likelihood, Mahalanobis Distance, and Support Vector Machine.

According to Figure 4c, although the best Maximum Likelihood Classification obtains an Overall Accuracy of $89.12 \%$, some misclassifications appear in this thematic map. For instance, some pixels which are classified as urban (red) appear in bare soil areas, as well as some road pixels in areas of bare soil. Moreover, due to the field observations and information from the Teide managers, an excess of $D$. bourgaeana appears in the classified image (too many yellow pixels). In addition, S. supranubius must be less abundant around $P$. canariensis in the ecosystem (top left in the thematic map). For the best Mahalanobis Distance method, similar misclassified pixels to those of the Maximum Likelihood Classification 


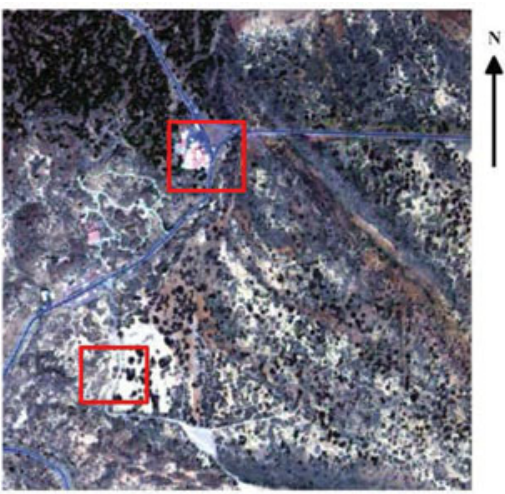

$\begin{array}{llllll}100 & 0 & 100 & 200 & 300 & 400 \mathrm{~m}\end{array}$
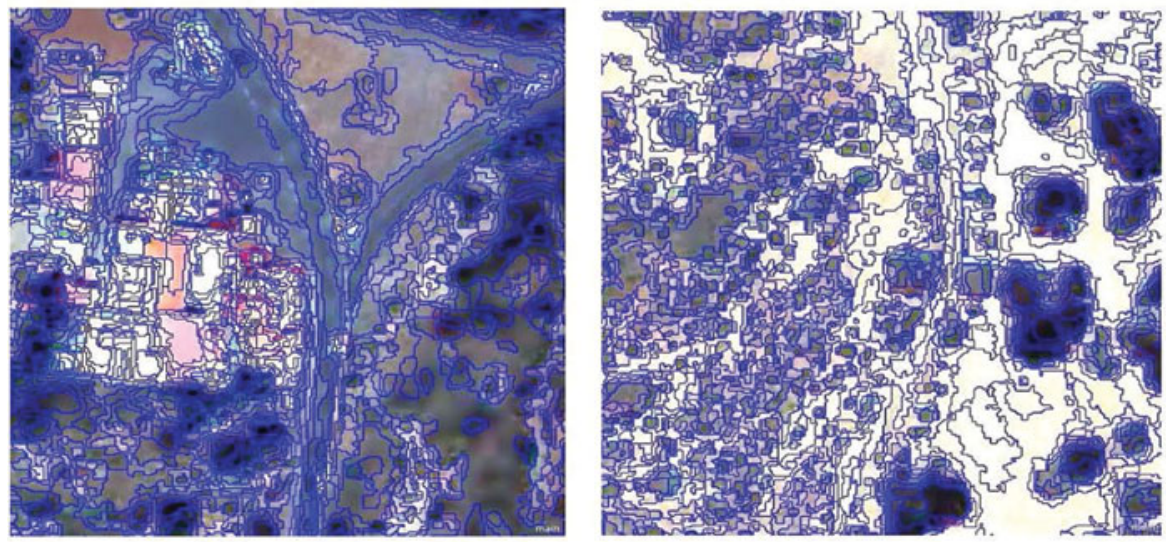

Figure 6. Multiresolution segmentation and spectral difference segmentation results.

Table 2. Quality results for the complete WV-2 bands (best results in bold).

\begin{tabular}{|c|c|c|c|c|c|c|}
\hline & \multicolumn{2}{|c|}{ Spectral Quality } & \multicolumn{3}{|c|}{ Spatial Quality } & \multirow{2}{*}{$\frac{\text { Global Quality }}{\mathrm{Q}}$} \\
\hline & SAM & Spectral ERGAS & Spatial ERGAS & FC & Zhou & \\
\hline GS & 4.098 & 1.704 & 0.899 & 0.842 & 0.736 & 0.935 \\
\hline FIHS & 3.781 & 1.683 & 0.894 & 0.840 & 0.719 & 0.898 \\
\hline HCS & 3.516 & 0.387 & 0.908 & 0.775 & 0.669 & 0.932 \\
\hline MTF_GLP & 3.212 & 1.245 & 0.903 & 0.785 & 0.650 & 0.961 \\
\hline MTF_GLP_HPM_NM & 3.872 & 0.334 & 0.888 & 0.809 & 0.706 & 0.921 \\
\hline WAVE_ATROUS & 4.588 & 1.753 & 0.749 & 0.935 & 0.994 & 0.879 \\
\hline WAT $\otimes F R A C$ & 4.187 & 1.445 & 0.824 & 0.864 & 0.892 & 0.901 \\
\hline
\end{tabular}

Table 3. Accuracy assessment of the pixel-based classification algorithms for each fused image (the best results are in bold).

\begin{tabular}{|c|c|c|c|c|c|c|}
\hline \multirow{2}{*}{$\frac{\text { Classification Techniques }}{\text { Pansharpening Algorithms }}$} & \multicolumn{2}{|c|}{ Maximum Likelihood } & \multicolumn{2}{|c|}{ Mahalanobis Distance } & \multicolumn{2}{|c|}{ Support Vector Machine } \\
\hline & Overall Accuracy & Kappa & Overall Accuracy & Kappa & Overall Accuracy & Kappa \\
\hline Multispectral & $85.06 \%$ & 0.79 & $72.89 \%$ & 0.64 & $89.60 \%$ & 0.85 \\
\hline GS & $82.73 \%$ & 0.76 & $74.28 \%$ & 0.65 & $88.45 \%$ & 0.85 \\
\hline FIHS & $83.71 \%$ & 0.77 & $76.14 \%$ & 0.67 & $88.83 \%$ & 0.84 \\
\hline HCS & $82.99 \%$ & 0.76 & $74.33 \%$ & 0.65 & $88.90 \%$ & 0.84 \\
\hline MTF_GLP & $85.36 \%$ & 0.8 & $74.87 \%$ & 0.66 & $88.51 \%$ & 0.83 \\
\hline MTF GLP HPM & $82.78 \%$ & 0.76 & $73.68 \%$ & 0.64 & $88.64 \%$ & 0.83 \\
\hline WAVE_ATROUS & $88.74 \%$ & 0.84 & $80.79 \%$ & 0.73 & $92.15 \%$ & 0.89 \\
\hline WAT $\otimes F R A C$ & $89.12 \%$ & 0.85 & $80.41 \%$ & 0.73 & $92.75 \%$ & 0.89 \\
\hline
\end{tabular}


a)

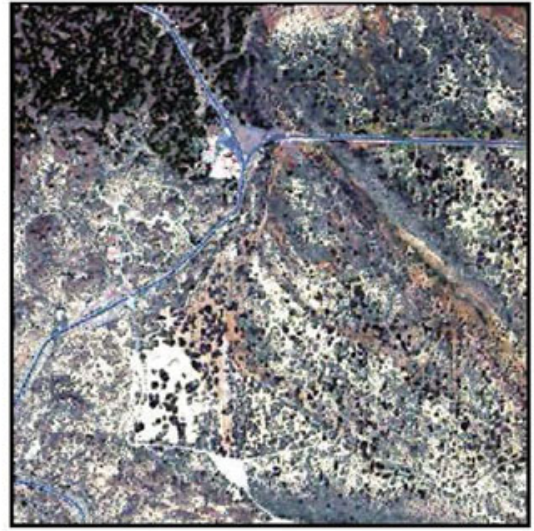

c)

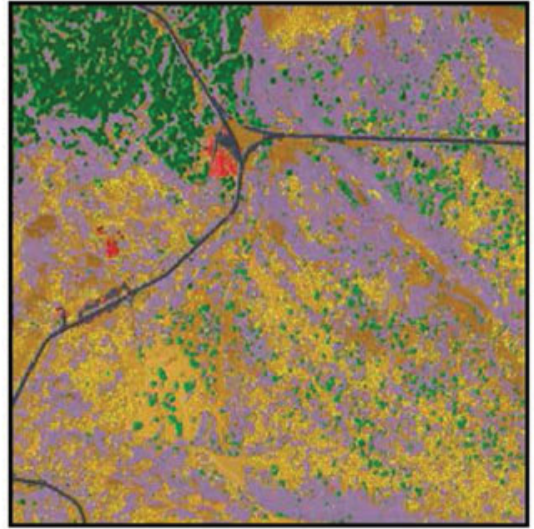

e)

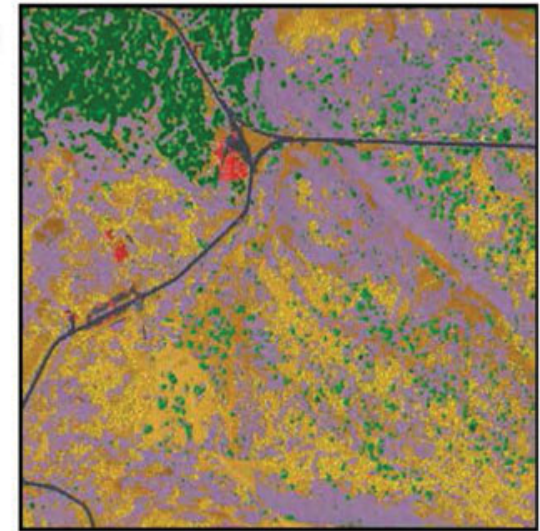

b)

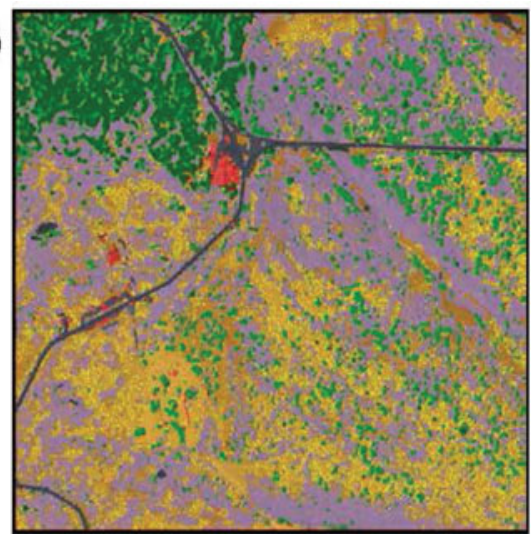

d)

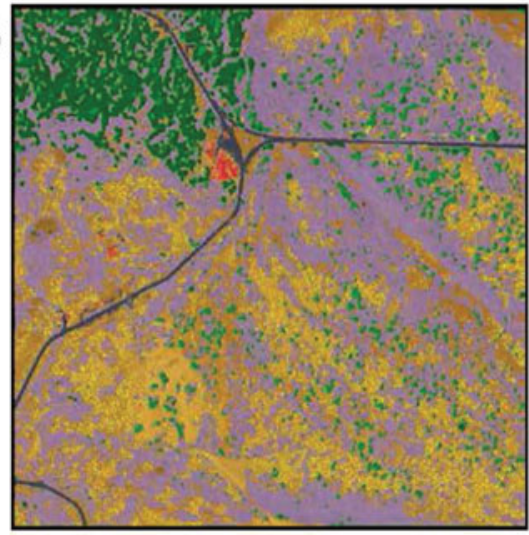

Urban

P. lasiospermus

Road

S. supranubius

P. canariensis

D. bourgaeana

Bare soil

Figure 7. (a) WAT $\otimes$ FRAC RGB color composite; and thematic maps: (b) Bayes; (c) Nearest Neighbor; (d) K-Nearest Neighbor; and (e) Support Vector Machine.

appear. Nevertheless, the abundance of pixels classified as D. bourgaeana decreases compared with the Maximum Likelihood result while S. supranubius class increases in some areas where, according to expert opinion, it does not have to appear in these areas. Finally, the Support Vector Machine thematic map achieves the highest Overall Accuracy (92.75\%). Despite the improvement using the Support Vector Machine classifier, the computation time with it was significantly higher, more than 24 hours, than the other 2 classifiers, which took a few minutes in the same computer.

In order to identify the best methodology (pansharpening + classification model) to properly discriminate the vegetation classes, Figure 5 displays the classification overall accuracy chart for each class in each pixelbased approach for the pansharpening algorithm achieving the best performance. Observing the classes, it is noted that Maximum Likelihood classifier obtains higher values in the different classes than other classifiers except for P. lasiospermus and bare soil, even though the best Overall Accuracy and Kappa coefficient is achieved by Support Vector Machine classifier. This fact is important due to the aim of the study, which is to obtain the best plant species classification map. However, as it was mentioned, Figure $4 \mathrm{c}$ shows some misclassifications when using Maximum Likelihood classifier. 


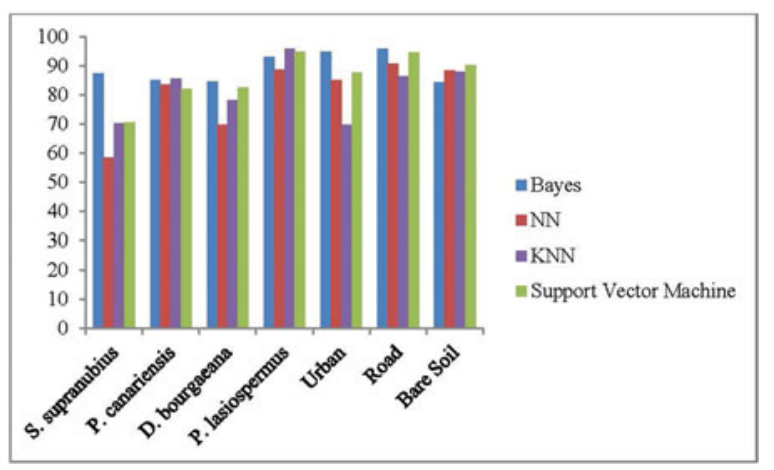

Figure 8. Classification overall accuracy in percentage (\%) of each class and classifier in the fused image. $X$ axis: classes; $Y$ axis: percentage value.

\section{Object-based classification results}

\section{Image segmentation}

The image was segmented using the aforementioned Multiresolution Segmentation technique to generate first, 8 different object-oriented segmentations to select the most suitable Image Layer Weight and Scale parameters. The segmentation parameters were selected by a visual evaluation and applying a Support Vector Machine classification technique with the training and testing samples obtained in the field work. Both the Overall Accuracy and the Kappa coefficient were analyzed in order to evaluate the most suitable segmentation parameters. The greater the accuracy, the better the adjustment of the segmentation parameters with the image objects. Tables 4 and 5 details some of the Scale parameters and criterion combinations used, as well as the classification accuracy obtained in each segmentation. Test Number 8 shows the most suitable segmentation for the Image Layer Weights and Scale parameters, which is revealed in the classification results.

Figure 6 shows a zoom of the segmentation results, in which objects preserve small shrubs which are difficult to delimitate.

\section{OBIA classification}

Once the objects are obtained from the segmentation techniques, classification algorithms can be applied. The classification algorithms analyzed and the parameters used are shown in Table 1.

Table 6 shows the Overall Accuracy and the Kappa coefficient for each object-based classification technique applied to each fused image. By analyzing the table, every classifier obtains the best accuracy result in the WAT $\otimes$ FRAC fused image. Overall Accuracy and Kappa coefficient values are similar to the pixel-based classification results (Table 3), with the Support Vector Machine classifier, once again, obtaining the best overall accuracy result. The table shows how the classification accuracy is, in general, improved in images fused with algorithms that preserve the spatial and spectral quality (WAVE_ATROUS and WAT $\otimes$ FRAC), compared with the original multispectral image. The most accurate thematic maps of each classifier are shown in Figure 7.

Figure 7 shows the WAT $\otimes$ FRAC fused image and each classification map using Bayes, Nearest Neighbor, KNearest Neighbor, and Support Vector Machine. In the case of the Bayes classifier some objects which are classified as urban areas appear as bare soil areas and road objects in areas of bare soil, like the Maximum Likelihood Classification in the pixel-based approach. In the Nearest Neighbor classification, the misclassifications obtained in the Bayes classifier are resolved, observing a more accurate thematic map at first sight, as well as K-Nearest Neighbor classifier, which shows a similar thematic map. Finally, the Support Vector Machine map is similar to the previous ones.

Figure 8 summarizes the classification overall accuracy, in percentage, of each class and for each OBIA classification approach applied to the WAT $\otimes$ FRAC fused image. Bayes provides a high percentage of accuracy, obtaining the highest results for most of the vegetation classes. While the Nearest Neighbor, the vegetation classes have a lower percentage of accuracy, achieving the lowest for $S$. supranubius. Regarding the K-Nearest Neighbor classifier, it achieves a high degree of accuracy for P. lasiospermus, which is a significant class of interest for the ecosystem management of this region. On the other hand, the misclassifications obtained in the other 3 types of vegetation improved with respect to the Nearest Neighbor classification. Support Vector Machine, even though achieving the highest Overall Accuracy and Kappa coefficient (Table 6), these results do not appear in the ones obtained in the classification accuracy of each class (Figure 8).

It is important to note the good results obtained using the WAT $\otimes$ FRAC algorithm in both pixel-based and object-based approaches. Although the best overall accuracy is obtained by the Support Vector Machine in both cases, not only the computation times for the pixel-based approach are much higher that for the OBIA approach but Maximum Likelihood Classification and Bayes classifier obtain higher accuracies for the majority of vegetation classes of interest. However, as it was mentioned, the visual assessment obtained with Maximum Likelihood classification does not fully correspond with the experts' opinion. This leads to the Bayes classification, at OBIA approach, applied to the WAT $\otimes$ FRAC fused image being the most suitable classifier in order to obtain fast and accurate thematic maps of these difficult heterogeneous shrub-land ecosystems. Even though it does not achieve the highest overall accuracy (Table 6), it is closer to the Support Vector Machine classifier but obtaining higher classification accuracies for each class. 
a)

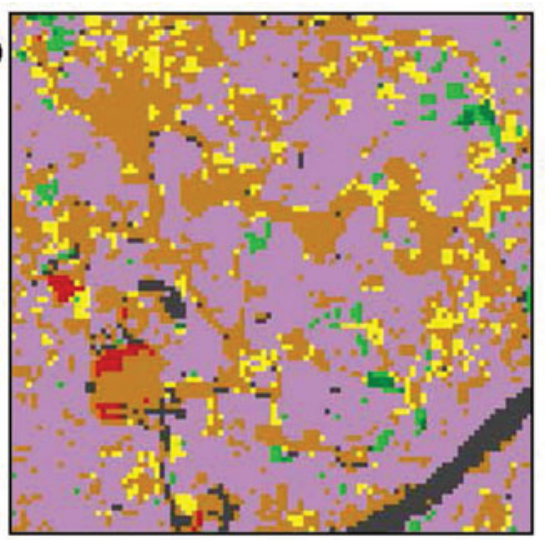

c)
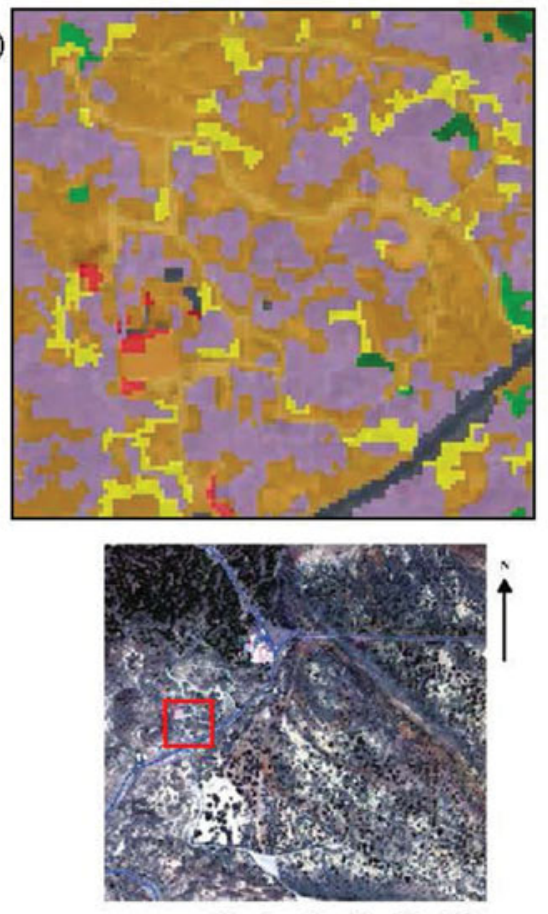

b)
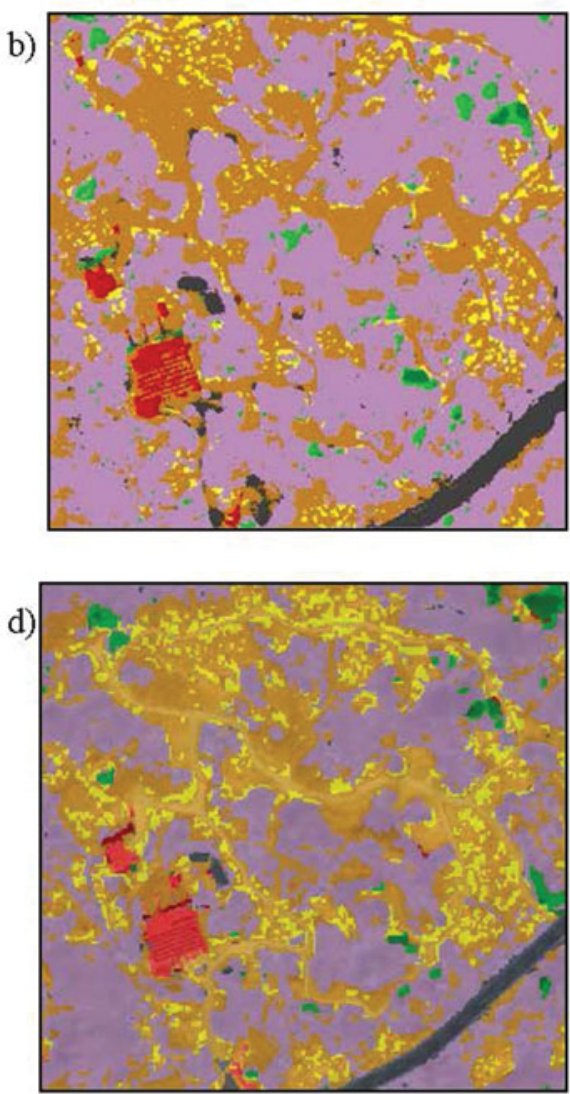

Urban

P. lasiospermus

Road

S. supramubius

P. canariensis

D. bourgaeana

Bare soil

Figure 9. Zoom of the thematic maps obtained by the SVM classifier applied at pixel-based approach in: (a) Original multispectral image and (b) WAT $\otimes$ FRAC fused image; and at OBIA approach in: (c) Original multispectral image and (d) WAT $\otimes$ FRAC fused image.

Table 4. Accuracy assessment of Image Layer Weight (Worldview-2 bands), and scale segmentation parameters (best result appears in bold).

\begin{tabular}{|c|c|c|c|c|c|c|}
\hline \multirow[b]{2}{*}{ Number } & \multicolumn{4}{|c|}{ Segmentation } & \multicolumn{2}{|c|}{ Classification } \\
\hline & Image Layer Weights & Scale & Shape & Compactness & Overall Accuracy & Kappa Coefficient \\
\hline 1 & $1,1,1,1,1,1,1,1$ & 5 & 0.1 & 0.5 & $78.67 \%$ & 0.70 \\
\hline 2 & $1,1,1,1,1,1,1,1$ & 10 & 0.1 & 0.5 & $88.11 \%$ & 0.83 \\
\hline 3 & $1,1,1,1,1,1,1,1$ & 15 & 0.1 & 0.5 & $87.97 \%$ & 0.83 \\
\hline 4 & $1,1,1,1,1,1,1,1$ & 20 & 0.1 & 0.5 & $88.00 \%$ & 0.83 \\
\hline 5 & $1,1,1,1,1,1,1,1$ & 12 & 0.1 & 0.5 & $88.08 \%$ & 0.83 \\
\hline 6 & $1,1,1,1,2,1,1,1$ & 12 & 0.1 & 0.5 & $88.20 \%$ & 0.83 \\
\hline 7 & $1,1,1,1,1,2,1,1$ & 12 & 0.1 & 0.5 & $87.92 \%$ & 0.83 \\
\hline 8 & $1,1,1,1,1,1,2,2$ & 12 & 0.1 & 0.5 & $88.29 \%$ & 0.83 \\
\hline
\end{tabular}


Table 5. Accuracy assessment of compactness and shape segmentation parameter using the Image Weight Layer:1, 1, 1, 1, 1, 1,2, 2 and with a Scale: 12 (best result appears in bold).

\begin{tabular}{|c|c|c|c|c|c|c|c|c|c|c|}
\hline & & \multicolumn{9}{|c|}{ Shape } \\
\hline & & 0.1 & 0.2 & 0.3 & 0.4 & 0.5 & 0.6 & 0.7 & 0.8 & 0.9 \\
\hline \multirow[t]{9}{*}{ Compactness } & 0.1 & 88.44 & 88.40 & 88.59 & 88.72 & 88.83 & 88.46 & 88.06 & 87.96 & 85.63 \\
\hline & 0.2 & 87.68 & 88.30 & 88.72 & 88.67 & 88.34 & 88.69 & 88.00 & 87.20 & 86.14 \\
\hline & 0.3 & 88.07 & 88.36 & 88.58 & 88.50 & 88.21 & 88.47 & 87.95 & 87.00 & 84.85 \\
\hline & 0.4 & 87.90 & 88.70 & 87.85 & 88.70 & 88.54 & 88.54 & 87.80 & 86.69 & 84.97 \\
\hline & 0.5 & 88.11 & 88.06 & 88.78 & 88.57 & 88.30 & 87.99 & 87.97 & 86.46 & 84.85 \\
\hline & 0.6 & 88.54 & 87.67 & 88.42 & 88.79 & 88.58 & 87.84 & 87.41 & 86.36 & 84.28 \\
\hline & 0.7 & 88.36 & 88.08 & 88.16 & 88.80 & 88.35 & 88.00 & 87.17 & 85.88 & 83.44 \\
\hline & 0.8 & 88.47 & 88.46 & 87.86 & 88.18 & 88.24 & 86.86 & 86.89 & 85.53 & 83.77 \\
\hline & 0.9 & 88.33 & 88.07 & 87.97 & 88.14 & 87.43 & 86.08 & 86.74 & 85.67 & 84.40 \\
\hline
\end{tabular}

Table 6. Accuracy assessment of the object-based classification algorithms for each fused and segmented (Multiresolution Segmentation and Spectral Difference) image (the best results are in bold).

\begin{tabular}{|c|c|c|c|c|c|c|c|c|}
\hline \multirow{2}{*}{$\frac{\text { Classification Techniques }}{\text { Pansharpening Algorithms }}$} & \multicolumn{2}{|c|}{ Bayes } & \multicolumn{2}{|c|}{ NN } & \multicolumn{2}{|c|}{ K-NN } & \multicolumn{2}{|c|}{ Support Vector Machine } \\
\hline & Ov. Acc. & Kappa & Ov. Acc. & Kappa & Ov. Acc. & Kappa & Ov. Acc. & Kappa \\
\hline Multispectral & $79.48 \%$ & 0.71 & $77.58 \%$ & 0.67 & $77.67 \%$ & 0.67 & $80.61 \%$ & 0.72 \\
\hline GS & $77.80 \%$ & 0.69 & $77.93 \%$ & 0.68 & $81.50 \%$ & 0.73 & $82.41 \%$ & 0.74 \\
\hline FIHS & $81.92 \%$ & 0.74 & $79.25 \%$ & 0.70 & $82.77 \%$ & 0.75 & $83.72 \%$ & 0.76 \\
\hline HCS & $78.27 \%$ & 0.70 & $79.1 \%$ & 0.70 & $82.30 \%$ & 0.74 & $82.72 \%$ & 0.74 \\
\hline MTF_GLP & $75.12 \%$ & 0.66 & $76.37 \%$ & 0.66 & $81.16 \%$ & 0.73 & $83.14 \%$ & 0.75 \\
\hline MTF_GLP_HPM & $78.27 \%$ & 0.70 & $77.92 \%$ & 0.68 & $82.55 \%$ & 0.74 & $83.18 \%$ & 0.75 \\
\hline WAVE_ATROUS & $86.04 \%$ & 0.80 & $82.84 \%$ & 0.75 & $85.22 \%$ & 0.78 & $87.68 \%$ & 0.82 \\
\hline WAT $\otimes F R A C$ & $89.14 \%$ & 0.84 & $84.07 \%$ & 0.77 & $88.54 \%$ & 0.83 & $89.39 \%$ & 0.85 \\
\hline
\end{tabular}

Note. Ov. Acc. = Overall Accuracy.

Table 7. Computation times (minutes) of the different classifiers in pixel based (using ENVI) and in OBIA (using eCognition) approaches.

\begin{tabular}{|c|c|c|c|c|c|c|c|}
\hline & \multicolumn{3}{|c|}{ Pixel-Based Approach } & \multicolumn{4}{|c|}{ OBIA Approach } \\
\hline & Maximum Likelihood & Mahalanobis Distance & Support Vector Machine & Bayes & NN & KNN & Support Vector Machine \\
\hline Computation Time (min) & 8 & 11 & 1,518 & 0.18 & 1.2 & 1.3 & 1.6 \\
\hline
\end{tabular}

Table 7 shows the computation times of each classifier in both approaches, using a computer with Windows 10 of 64 bits, Intel ${ }^{\circledR}$ Core $^{\mathrm{TM}}$ i7-490 CPU @ $360 \mathrm{GHz}$ with 32.0 GB of RAM. Note that the computation times of OBIA classifiers were significantly lower than the ones using the pixel-based approach, especially the Support Vector Machine, which took hours to obtain the classification maps in the pixel-based approach.

In order to visually assess how the pansharpening process improves the result in the thematic maps, a final figure (Figure 9) shows zooms of the thematic maps obtained using both Support Vector Machine algorithm on the original multispectral and the WAT $\otimes$ FRAC fused images in both pixel and OBIA approaches. We have decided to show Support Vector Machine results because it obtained the most suitable classification in the pixelbased approach and, thus, it is possible to compare the same classification result using the same classifier in the 2 different approaches (pixel- and object-based). The importance of pansharpening is observed as some classes of interest are not well labeled in the original multispectral thematic maps (Figure 9a). On the other hand, buildings are erroneously classified as bare soil in the original multispectral image and road limits are stepped due to the pixel size in the original image. Moreover, the poor quality of the classification is appreciated when applying OBIA to the Multispectral image, however, when it is applied to the fused image, the contours of the covers are smoother and it reduces the salt and pepper effect.

\section{Conclusions}

The main objective of the presented work was to study the pansharpening influence on obtaining accurate thematic maps, applying pixel-based and OBIA classification techniques on VHR imagery from a complex and heterogeneous ecosystem. Thus, 7 different pansharpening techniques (GS, FIHS, HCS, MTF_GLP, MTF_GLP_HPM, WAVE_ATROUS, and WAT $\otimes F R A C)$ were applied to achieve the highest spatial resolution of the multispectral 
bands while preserving its original spectral information. Several classification algorithms were next applied at the pixel-based level (Maximum Likelihood Classification, Mahalanobis Distance, and Support Vector Machine) and at the object-based level (Bayes, Nearest Neighbor, KNearest Neighbor, and Support Vector Machine).

First, visual and quantitative quality assessment of the 7 pansharpening techniques was performed. A good compromise between the spatial and spectral quality is a requirement of the study. This compromise is noted after analyzing the results from the 6 quality metrics. MTF methods achieve the best spectral performance, while WAVE_ATROUS achieves the best spatial quality. WAT $\otimes$ FRAC provides a suitable balance between the geometrical representation of structures and representation of original spectral information.

Next, detailed accuracy results were performed for the classified maps. We conclude the importance of the pansharpening step in ecosystems with small and mixed vegetation, where the spatial information is critical and should be well incorporated in order to generate accurate thematic maps. It is important to highlight the difficulty in classifying some types of vegetation due to the complexity of this heterogeneous shrubland ecosystem with small vegetation species such as D. bourgaeana. Hence, the major impact on the mapping of different types of vegetation is the misclassification created within the plant species, due to their spectral similarity and the mixing contributions from different covers in some pixels. Thus, it is important to create a reliable training sample database, which allows an accurate supervised classification to be made. As mentioned, experts from the Teide National Park helped to obtain the ground truth samples used for training and testing. This assumption leads us back to the importance of obtaining a fused image with a high spatial quality that allows us to differentiate some species from others, avoiding pixel misclassification but also preserving the original spectral information.

In both classification approaches, the WAT $\otimes$ FRAC fused image achieves the best thematic map with every classification method except for Mahalanobis Distance using the pixel-based approach. The highest Overall Accuracy is obtained by the Support Vector Machine, applied to the WAT $\otimes$ FRAC fused image for both approaches, having similar results with Maximum Likelihood in the pixel-based approach and with Bayes in the OBIA approach. Moreover, Maximum Likelihood, as well as Bayes, obtained the highest accuracies for most vegetation classes, even though the visual results in the Maximum Likelihood classification are not fully satisfactory. In addition, the computation time of the Support Vector Machine is higher than other classifiers, being considerably high in the pixel-based approach. Thus, we conclude that Bayes classifier applied in an object-based approach is the most suitable algorithm for this ecosystem area.

Despite the accurate classification results obtained, some limitations for both studied approaches have to be mentioned. In the case of the pixel approach, the main limitation is the presence of mixed pixels located in boundaries between classes. Moreover, the quantity of data to be processed is higher than in the OBIA approach, in which objects are processed instead of pixels. On the other hand, in the OBIA approach there is a high dependency on the segmentation parameters, which are specific for each image. There is no global protocol for setting the segmentation parameters and the user must analyze which segmentation parameters are more suitable depending on the image.

In conclusion, after an extensive testing of pansharpening and classification algorithms, we have obtained a methodology that provides a good performance in these heterogeneous regions with small and mixed shrubs, obtaining challenging thematic maps of land-protected areas for studying the state of conservation of natural resources.

Future research will include ancillary data, such as Lidar and SAR imagery, as well as specific vegetation indices and texture parameters in the classification approach in order to obtain more accurate thematic maps not only in shrubland ecosystems, but also in coastal and shallow water natural areas. This methodology could be applied not only to Teide National Park ecosystem but to other similar ecosystems around the world.

\section{Acknowledgments}

We wish to acknowledge the Teide National Park conservation managers (Jose Luis Martín Esquivel and Manuel Marrero Gómez) for defining the classes of interest and examining the results obtained, and Ángel Garcia-Pedrero for his implementation of the HCS code.

\section{Funding}

This research has been supported by the ARTEMISAT (CGL2013-46674-R) and ARTEMISAT-2 (CTM2016-77733-R) project, funded by the Spanish Ministerio de Economía y Competitividad and Fondo Europeo de Desarrollo Regional (FEDER). This work was completed while E. I-U was a Ph.D. student in the IOCAG Doctoral Program in Oceanography and Global Change and funded by the Spanish Ministerio de Economía $y$ Competitividad with a FPI grant (BES-2014-069426).

\section{ORCID}

Consuelo Gonzalo-Martín (0 http://orcid.org/0000-0002-08049293 


\section{References}

Adler-Golden, S.M., Matthew, M.W., Bernstein, L.S., Levine, T.Y., Berk, A., Richtsmeier, S.C., Acharya, P.K., Anderson, G.P., Felde, J.W., and Gardner, J. 1999. "Atmospheric correction for shortwave spectral imagery based on MODTRAN4." In Proceedings of SPIE, Imaging Spectronomy V (Vol. 3753), edited by M. R. Descour and S. S. Shen, pp. 6169. Bellingham, WA: SPIE.

Aiazzi, B., Alparone, L., Baronti, S., and Garzelli, A. 2002. "Context-driven fusion of high spatial and spectral resolution images based on oversampled multiresolution analysis." IEEE Transactions on Geoscience and Remote Sensing, Vol. 40: pp. 2300-2312.

Aiazzi, B., Alparone, L., Baronti, S., Garzelli, A., and Selva, M. 2006. "MTF-tailored multiscale fusion of high resolution MS and Pan imagery." Photogrammetric Engineering and Remote Sensing, Vol. 72: pp. 591-596.

Alimuddin, I., Sumantyo, J.T.S., and Kuze, H. 2012. “Assessment of pan-sharpening methods applied to image fusion of remotely sensed multi-band data." International Journal of Applied Earth Observation and Geoinformation, Vol. 18: pp. 165-175.

Alparone, L., Aiazzi, B., Baronti, S., Garzelli, A., Nencini, F., and Selva, M. 2008. "Multispectral and panchromatic data fusion assessment without reference." Photogrammetric Engineering and Remote Sensing, Vol. 74(No. 2): pp. 193200.

Alparone, L., Baronti, S., Aiazzi, B., and Garzelli, A. 2016. “Spatial methods for multispectral pansharpening: Multiresolution analysis demystified." IEEE Transactions on Geoscience and Remote Sensing, Vol. 54(No. 5): pp. 2563-2576.

Alparone, L., Baronti, S., Garzelli, A., and Nencini, F. 2004. “A global quality measurement of pan-sharpened multispectral imagery." Geoscience and Remote Sensing Letters, Vol. 1(No. 4): pp. 313-317.

Amolins, K., Zhang, Y., and Dare, P. 2007. "Wavelet based image fusion techniques-An introduction, review and comparison." ISPRS Journal of Photogrammetry and Remote Sensing, Vol. 62(No. 4): pp. 249-263.

Amro, I., Mateos, J., Vega, M., Molina, R., and Katsaggelos, A.K. 2011. "A survey of classical methods and new trends in pansharpening of multispectral images." EURASIP Journal on Advances in Signal Processing, Vol. 1: p. 79.

Aplin, P. 2004. "Remote sensing: Land cover." Progress in Physical Geography, Vol. 28(No. 2): pp. 283-293.

Arozena-Concepción, M., and Beltrán-Yanes, E. 2006. "Geografía de la vegetación de las coladas domáticas del atrio de las Cañadas del Teide (Tenerife. I. Canarias)." Serie Geográfica-Biogeografía: Distribuciones, Dinámicas y Diversidad, Vol. 13: pp. 43-64.

Baatz, M., Benz, U., Dehghani, S., Heynen, M., Höltje, A., Hofmann, P., Lingenfelder, I., Mimler, M., Sohlbach, M., and Weber, M. 2001. eCognition User Guide. Munich, Germany: Definiens Imaging $\mathrm{GmbH}$.

Blaschke, T., Lang, S., and Hay, G. 2008. Object-Based Image Analysis: Spatial Concepts for Knowledge-Driven Remote Sensing Applications. Berlin, Germany: Springer Science and Business Media.

Bonet, F.J., Zamora, R., Gastón, A., Molina, C., and Bariego, P. 2009. "Matorrales pulvinulares orófilos europeos meridionales." VV. AA., Bases ecológicas preliminares para la conservación de los tipos de hábitat de interés comunitario en España. Gobierno de España. Ministerio de Medio Ambiente, y Medio Rural y Marino.

Burnett, C., Aaviksoo, K., Lang, S., Langanke, T., and Blaschke, T. 2003. "An object-based methodology for mapping mires using high resolution imagery." In Proceedings of Ecohydrological Processes in Northern Wetlands, edited by A. Jarvet and E. Lode, pp. 239-244. Tallinn, Estonia: Tartu University Press.

Burt, P.J., and Adelson, E.H. 1983. "The Laplacian pyramid as a compact image code." IEEE Transactions on Communications, Vol. 31(No. 4): pp. 532-540.

Carper, W., Lillesand, T., and Kiefer, R. 1990. "The use of intensity-hue-saturation transformations for merging SPOT panchromatic and multispectral image data." Photogrammetric Engineering and Remote Sensing, Vol. 56: pp. 459-467.

Chavez, P.S., Stuart, J., Sides, C., and Anderson, J.A. 1991. “Comparison of three different methods to merge multiresolution and multispectral data: Landsat TM and SPOT panchromatic." Photogrammetric Engineering and Remote Sensing, Vol. 57: pp. 259-303.

Congalton, R.G. 1991. "A review of assessing the accuracy of classifications of remotely sensed data." Remote Sensing of Environment, Vol. 37(No. 1): pp. 35-46.

Dronova, I. 2015. "Object-based image analysis in wetland research: A review.” Remote Sensing, Vol. 7(No. 5): pp. 63806413.

Dutilleux, P., Aiguier, C., and Joliot, R. 1987. “An implementation of the 'algorithm à trous' to compute the wavelet transform." In Wavelets: Time-Frequency Methods and Phase Space (2nd ed.), edited by J.M. Combes, A. Grossman, and Ph. Tchamitchian. New York, NY: Springer-Verlag.

ENVI. 2004. ENVI User's Guide. Boulder, CO: Research Systems Inc.

Franklin, S., and Wulder, M. 2002. Remote sensing methods in medium spatial resolution satellite data land cover classification of large areas. Progress in Physical Geography, Vol. 26(No. 2): pp. 173-205.

Gao, B.C., Montes, M.J., Davis, C.O., and Goetz, A.F. 2009. "Atmospheric correction algorithms for hyperspectral remote sensing data of land and ocean." Remote Sensing of Environment, Vol. 113: pp. S17-S24.

Garcia-Pedrero, A., Gonzalo-Martin, C., Fonseca-Luengo, D., and Lillo-Saavedra, M. 2015. "A GEOBIA methodology for fragmented agricultural landscapes.” Remote Sensing, Vol. 7(No. 1): pp. 767-787.

Garzón-Machado, V., Del Arco-Aguilar, M.J., and Pérez-DePaz, P.L. 2011. "A tool set for description and mapping vegetation on protected natural areas: An example from the Canary Islands." Biodiversity and Conservation, Vol. 20(No. 14): pp. 3605-3625.

Gillespie, A.R., Kahle, A.B., and Walker, R.E. 1987. "Color enhancement of highly correlated images-II. Channel ratio and 'chromaticity' transform techniques." Remote Sensing of Environment, Vol. 22: pp. 343-365.

González-Audícana, M., Saleta, J.L., Catalán, R.G., and García, R. 2004. "Fusion of multispectral and panchromatic images using improved IHS and PCA mergers based on wavelet decomposition." IEEE Transactions on Geoscience and Remote Sensing, Vol. 42: pp. 12911299. 
González-Lemus, N., Carracedo-Gómez, J.C., and DurbánVillonga, M. 2009. "El Parque Nacional del Teide: Patrimonio mundial de la UNESCO. Anuario de Estudios Atlánticos, Vol. 1(No. 55): pp. 519-568.

Gonzalo-Martín, C., and Lillo-Saavedra, M. 2008. "Influence of source images spatial characteristics on the global quality of fused images." Revista de Teledetección, Vol. 30: pp. 33-46.

Goodin, D.G., Anibas, K.L., and Bezymennyi, M. 2015. "Mapping land cover and land use from object-based classification: An example from a complex agricultural landscape." International Journal of Remote Sensing, Vol. 36(No. 18): pp. 4702-4723.

Ibarrola-Ulzurrun, E., Gonzalo-Martin, C., Marcello-Ruiz, J., Garcia-Pedrero, A., and Rodriguez-Esparragon, D. 2017. "Fusion of high resolution multispectral imagery in vulnerable coastal and land ecosystems." Sensors, Vol. 17(No. 2): p. 228.

Isbell, F., Calcagno, V., Hector, A., Connolly, J., Harpole, W.S., Reich, P.B., Scherer-Lorenzen, M., Schmid, B., Tilman, D., and Van Ruijven, J. 2011. "High plant diversity is needed to maintain ecosystem services.” Nature, Vol. 477(No. 7363): pp. 199-202.

Khare, S., and Ghosh, S. 2016. "Satellite remote sensing technologies for biodiversity monitoring and its conservation." International Journal of Advanced Earth Science and Engineering, Vol. 5(No. 1): pp. 375-389.

Kpalma, K., El-Mezouar, M.C., and Taleb, N. 2014. "Recent trends in satellite image pan-sharpening techniques." Paper presented at the 1st International Conference on Electrical, Electronic and Computing Engineering, Vrnjačka Banja, Serbia, June 2014.

Kruse, F., Lefkoff, A., Boardman, J., Heidebrecht, K., Shapiro, A., Barloon, P., and Goetz, A. 1993. "The spectral image processing system (SIPS) - Interactive visualization and analysis of imaging spectrometer data." Remote Sensing of Environment, Vol. 44(No. 2): pp. 145-163.

Kyncl, T., Suda, J., Wild, J., Wildová, R., and Herben, T. 2006. "Population dynamics and clonal growth of Spartocytisus supranubius (Fabaceae), a dominant shrub in the alpine zone of Tenerife, Canary Islands." Plant Ecology, Vol. 186(No. 1): pp. 97-108.

Laben, C.A., and Brower, B.V. 2000. "Process for enhancing the spatial resolution of multispectral imagery using pansharpening." U.S. Patent No. 6,011,875. Washington, DC: U.S. Patent and Trademark Office.

Lantz, N.J., and Wang, J. 2013. "Object-based classification of Worldview-2 imagery for mapping invasive common reed, Phragmites australis." Canadian Journal of Remote Sensing, Vol. 39(No. 4): pp. 328-340.

Li, X., He, M., and Zhang, L. 2013. "Hyperspherical color transform based pansharpening method for WorldView-2 satellite images. Paper presented at the IEEE 8th Conference on Industrial Electronics and Applications, Melbourne, Australia, June 2013.

Li, X., Li, L., and He, M. 2012. "A novel pansharpening algorithm for WorldView-2 satellite images." Paper presented at the International Conference on Industrial and Intelligent Information, Singapore, March 2012.

Lillo-Saavedra, M., and Gonzalo, C. 2006. "Spectral or spatial quality for fused satellite imagery: A trade-off solution using the wavelet à trous algorithm." International Journal of Remote Sensing, Vol. 27(No. 7): pp. 1453-1464.
Lillo-Saavedra, M., Gonzalo, C., Arquero, A., and Martinez, E. 2005. "Fusion of multispectral and panchromatic satellite sensor imagery based on tailored filtering in the Fourier domain." International Journal of Remote Sensing, Vol. 26(No. 6): pp. 1263-1268.

Lillo-Saavedra, M., Gonzalo, C., and Lagos, O. 2011. “Toward reduction of artifacts in fused images." International Journal of Applied Earth Observation and Geoinformation, Vol. 13: pp. 368-375.

Lu, D., and Weng, Q. 2007. “A survey of image classification methods and techniques for improving classification performance." International Journal of Remote Sensing, Vol. 28(No. 5): pp. 823-870.

Marangoz, A.M., Oruç, M., Karakış, S., and Şahin, H. 2006. "Comparison of pixel-based and object-oriented classification using IKONOS imagery for automatic building extraction-Safranbolu testfield." Paper presented at the Fifth International Symposium Turkish-German Joint Geodetic Days, Berlin, Germany, March 2006.

Marcello, J., Eugenio, F., Perdomo, U. and Medina, A. 2016. "Assessment of atmospheric algorithms to retrieve vegetation in natural protected areas using multispectral high resolution imagery." Sensors, Vol. 16(No. 10): p. 1624.

Marcello, J., Medina, A., and Eugenio, F. 2013. "Evaluation of spatial and spectral effectiveness of pixel-level fusion techniques." Geoscience and Remote Sensing Letters, Vol. 10(No. 3): pp. 432-436.

Martín-Osorio, V.E., Wildpret-De La Torre, W., and Hernández-Bolaños, B. 2005. "Avances significativos en la elaboración de la base de datos georreferenciada de Flora y Vegetación del Parque Nacional del Teide, Tenerife, Islas Canarias mediante un Sistema de Información Geobotónica." Vieraea: Folia Scientarum Biologicarum Canariensium, Vol. 33: pp. 345-358.

Núnez, J., Otazu, X., Fors, O., Prades, A., Palà, V., and Arbiol, R. 1999. "Multiresolution-based image fusion with additive wavelet decomposition." IEEE Transactions on Geoscience and Remote Sensing, Vol. 37: pp. 1204-1211.

Oruc, M., Marangazoz, M., and Buyuksalih, G. 2004. “Comparison of pixel-based and object-oriented classification approaches using Landsat-7 ETM spectral bands.” Paper presented at the XX ISPRS Congress, Istanbul, Turkey, July 2004.

Otto, R., García-Del-Rey, E., Méndez, J., and FernándezPalacios, J.M. 2012. "Effects of thinning on seed rain, regeneration and understory vegetation in a Pinus canariensis plantation (Tenerife, Canary Islands)." Forest Ecology and Management, Vol. 280: pp. 71-81.

Padwick, C., Deskevich, M., Pacifici, F., and Smallwood, S. 2010. "WorldView-2 pan-sharpening." Paper presented at the ASPRS 2010 Annual Conference, San Diego, CA, April 2010.

Pakzad, K., Lúcio, G., Mota, A., Meirelles, M.S., Luiz, H., Coutinho, C., and Feitosa, R.Q. 2003. "Automatic interpretation of vegetation areas in Brazil." Paper presented at the Joint Workshop of ISPRS Working Groups I/2, I/5, IC WG II/IV and the EARSeL Special Interest Group, Hannover, Germany, October 2003.

Peña-Barragán, J.M., Ngugi, M.K., Plant, R.E., and Six, J. 2011. "Object-based crop identification using multiple vegetation indices, textural features and crop phenology." Remote Sensing of Environment, Vol. 115(No. 6): pp. 1301-1316. 
Pohl, C. 2014. "Challenges of remote sensing image fusion to optimize earth observation data exploitation." European Scientific Journal, Vol. 9: pp. 355-365.

Rodríguez-Esparragón, D. 2015. Evaluación y desarrollo de métricas de calidad espacial y espectral para aplicaciones de fusión de imágenes multiespectrales de teledetección de alta resolución. Thesis, Universidad Las Palmas de Gran Canaria, Gran Canaria, Spain.

Rodríguez-Esparragón, D., Marcello-Ruiz, J., Medina-Machín, A., Eugenio-González, F., Gonzalo-Martín, C., and GarcíaPedrero, A. 2014. "Evaluation of the performance of the spatial assessment of pansharpened images." Paper presented at the IEEE International Geoscience and Remote Sensing Symposium (IGARSS), Quebec City, Canada, July 2014.

Ruocco, M., Bertoni, D., Sarti, G., and Ciccarelli, D. 2014. "Mediterranean coastal dune systems: Which abiotic factors have the most influence on plant communities?" Estuarine, Coastal and Shelf Science, Vol. 149: pp. 213-222.

Shettigara, V.K. 1992. "A generalized component substitution technique for spatial enhancement of multispectral images using a higher resolution data set." Photogrammetric Engineering and Remote Sensing, Vol. 58: pp. 561-567.

Shridhar, J.D., and Alvarinho, L.J. 2013. “A spectral index ratiobased Antarctic land-cover mapping using hyperspatial 8band WorldView-2 imagery." Polar Science, Vol. 7(No. 1): pp. 18-38.

Thomas, C., Ranchin, T., Wald, L., and Chanussot, J. 2008. "Synthesis of multispectral images to high spatial resolution: A critical review of fusion methods based on remote sensing physics." IEEE Transactions on Geoscience and Remote Sensing, Vol. 46(No. 5): pp. 1301-1312.

Tu, T.M., Hsu, C.L., Tu, P.Y., and Lee, C.H. 2012. “An adjustable pan-sharpening approach for IKONOS/QuickBird/ GeoEye-1/WorldView-2 imagery." IEEE Journal of Selected Topics in Applied Earth Observations and Remote Sensing, Vol. 5(No. 1): pp. 125-134.
Tu, T.M., Su, S.C., Shyu, H.C., and Huang, P.S. 2001. “A new look at IHS-like image fusion methods." Information Fusion, Vol. 2(No. 3): pp. 177-186.

Vivone, G., Alparone, L., Chanussot, J., Dalla Mura, M., Garzelli, A., Licciardi, G., Restaino, R., and Wald, L. 2015. "A critical comparison among pansharpening algorithms." IEEE Transactions on Geoscience and Remote Sensing, Vol. 53(No. 5): pp. 2565-2586.

Wald, L. 2000. "Quality of high resolution synthesised images: Is there a simple criterion?" In Proceedings of the Third Conference Fusion of Earth Data: Merging Point Measurements, Raster Maps and Remotely Sensed Images, edited by T. Ranchin and L. Wald, pp. 99-103 Nice, France: SEE/URSICA.

Wald, L., Ranchin, T., and Mangolini, M. 1997. "Fusion of satellite images of different spatial resolutions: assessing the quality of resulting images." Photogrammetric Engineering and Remote Sensing, Vol. 63(No. 6): pp. 691-699.

Walsh, S.J., Mccleary, A.L., Mena, C.F., Shao, Y., Tuttle, J.P., González, A., and Atkinson, R. 2008. "QuickBird and Hyperion data analysis of an invasive plant species in the Galapagos Islands of Ecuador: Implications for control and land use management." Remote Sensing of Environment, Vol. 112(No. 5): pp. 1927-1941.

Wang, Z., and Bovik, A.C. 2002. "A universal image quality index.” IEEE Signal Letter, Vol. 9(No. 3): p. 4.

Wildpret de la Torre, W. 2001. "Consideraciones sobre la fitobiodiversidad de las cañadas del Teide." Paper presented at the Curso de acreditación de conocimientos para ejercer de guía en el Parque Nacional del Teide, Tenerife, Spain.

Wu, B., Fu, Q., Sun, L., and Wang, X. 2015. "Enhanced hyperspherical color space fusion technique preserving spectral and spatial content." Journal of Applied Remote Sensing, Vol. 9(No. 1): pp. 097291-097291.

Zhou, J., Civco, D., and Silander, J. 1998. “A wavelet transform method to merge Landsat TM and SPOT panchromatic data." International Journal of Remote Sensing, Vol. 19(No. 4): pp. 743-757. 